УДК 662.311.1

РАСЧЕТ УДЕЛЬНОЙ МАССОВОЙ СКОРОСТИ ВЫГОРАНИЯ НЕФТЕПРОДУКТОВ

\title{
CALCULATION OF THE SPECIFIC MASS BURN-UP RATE OF PETROLEUM PRODUCTS
}

\author{
С.М. Хуснутдинова, Ф.Ш. Хафизов, И.Ф. Хафизов, \\ Р.Ф. Мингазетдинов
}

Уфимский государственный нефтяной технический университет, г. Уфа, Российская Федерация

Sumbul M. Khusnutdinova, Fanil Sh. Khafizov, Ildar F. Khafizov, Rasim F. Mingazetdinov

\section{Ufa State Petroleum Technological University, Ufa, Russian Federation e-mail: sumbulryamova993@gmail.com}

Аннотация. На производственных объектах для определения безопасных расстояний при воздействии теплового излучения на персонал и материальные объекты в случае пожара используется величина массовой скорости выгорания горящего вещества. Удельная массовая скорость выгорания используется для расчета интенсивности теплового излучения и определяется экспериментально. Авторами исследованы методы расчета данной величины, применимые для горючих и легковоспламеняющихся жидких топлив. В настоящее время значения величин удельной массовой скорости выгорания приводятся в различных справочных материалах для ограниченного ряда нефтепродуктов. Значение удельной массовой скорости выгорания для простых (однокомпонентных) веществ можно также вычислить расчетным путем. Формулы расчета данной величины в теории применимы как для простых, так и для сложных веществ, при этом 
возникает необходимость расчета величин удельной теплоты сгорания и испарения, удельной теплоемкости вещества. Однако процесс горения сложных топлив существенно отличается в связи с поэтапным выгоранием отдельных фракций в их составе, поэтому для сложных веществ расчет должен производиться с учетом изменения плотности и температуры в процессе горения.

Целью исследования является усовершенствование метода определения удельной массовой скорости выгорания нефтепродуктов, являющихся многокомпонентными, с разработкой номограммы и формулы расчета, которые позволят определить величину удельной массовой скорости выгорания, зная плотность нефтепродукта при нормальных условиях и его температуру кипения.

Abstract. At production facilities, in order to determine safe distances when exposed to thermal radiation on personnel and material objects in the event of a fire, the value of the mass burnout rate of the burning substance is used. The specific mass burn-up rate is used to calculate the intensity of thermal radiation and is determined experimentally. The authors investigated the methods for calculating this value, which are applicable to combustible and flammable liquid fuels. Currently, the values of the specific mass burn-up rate are given in various reference materials for a limited number of petroleum products. The value of the specific mass burn-up rate for simple (one-component) substances can also be calculated. The formulas for calculating this value in theory are applicable for both simple and complex substances, while it becomes necessary to calculate the values of the specific heats of combustion and evaporation, the specific heat capacity of a substance. However, the combustion process of complex fuels differs significantly due to the gradual burnout of individual fractions in their composition, therefore, for complex substances, the calculation should be made taking into account the density and temperature changes during the combustion process. 
The aim of the study is to improve the method for determining the specific mass burn-up rate of multicomponent oil products, with the development of a nomogram and a calculation formula that will determine the value of the specific mass burn-up rate, knowing the density of the oil product under normal conditions and its boiling point.

Ключевые слова: пожарный риск; интенсивность теплового излучения; удельная массовая скорость выгорания; удельная теплота сгорания; удельная теплота испарения; удельная теплоемкость; многокомпонентное вещество

Keywords: fire risk; intensity of thermal radiation; specific mass burn-up rate; specific heat of combustion; specific heat of vaporization; specific heat capacity, complex substance

Удельная массовая скорость выгорания m' - это масса горючего вещества, которая выгорает в единицу времени с единицы площади пожара,

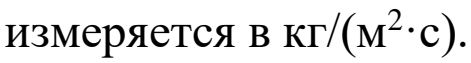

$$
\text { Эмпирическая формула } \mathrm{m}^{\prime}=\mathrm{m} /\left(S_{\text {п. }} \mathrm{t}\right) \text {, }
$$

где m - масса вещества, кг;

$S_{\text {п }}$ - площадь пожара, м $^{2}$

$\mathrm{t}$ - длительность горения, с [1].

Массовая скорость выгорания используется для определения интенсивности теплового излучения при прогнозировании рисков возникновения пожаров на производствах, в частности, при возможности пожара пролива. Показатели интенсивности теплового излучения необходимы для определения безопасных расстояний при воздействии теплового излучения на людей, производственные здания и сооружения, оборудование. 
В настоящее время показатель m' определяется экспериментальным путем. В различных справочных материалах на сегодняшний день приведены экспериментально-проверенные величины m' для небольшого ряда нефтепродуктов, в таблице 1 приведены значения m' для некоторых нефтепродуктов.

Таблица 1. Скорость выгорания горючих и легковоспламеняющихся топлив

\begin{tabular}{|l|c|}
\hline Нефтепродукт & $\begin{array}{c}\text { Скорость выгорания, } \\
\kappa г /\left(\mathrm{M}^{2} \cdot \mathrm{c}\right)\end{array}$ \\
\hline Нефть & $0,02-0,03$ \\
\hline Мазут & $0,02-0,03$ \\
\hline Дизтопливо & $0,05-0,06$ \\
\hline Керосин & $0,045-0,055$ \\
\hline Бензин & $0,045-0,053$ \\
\hline
\end{tabular}

Значения удельной массовой скорости выгорания небольшого ряда топлив приведены также в Методике определения расчетных величин пожарного риска на производственных объектах, утверждённой приказом МЧС России от 10 июля 2009 г. № 404 (Методика).

Величину массовой скорости выгорания для простых (однокомпонентных) веществ можно вычислить расчетным путем, используя следующую формулу [1, 2]:

$$
\mathrm{m}^{\prime}=\frac{0.001 \cdot \mathrm{H}}{\mathrm{L}+\mathrm{C}(\mathrm{Tb}-\mathrm{Ta})},
$$

где $\mathrm{H}$ - удельная теплота сгорания топлива, кДж/кг;

$\mathrm{L}$ - удельная теплота испарения жидкости, кДж/кг;

$\mathrm{C}$ - удельная теплоемкость жидкости, кДж/(кг·К);

$\mathrm{Tb}$ - температура кипения жидкости при атмосферном давлении, К;

Та - начальная температура жидкости, К.

Нами исследована возможность применения формулы (1) для расчета величины массовой скорости выгорания сложных веществ (в частности, для 
горючих и легковоспламеняющихся жидких топлив). В первую очередь, мы провели лабораторный эксперимент, определив величину $\mathrm{m}^{\prime}$ для индивидуального вещества бензола (получено в результате опыта значение $\left.\mathrm{m}^{\prime} \approx 0,04 \quad \kappa \Gamma /\left(\mathrm{M}^{2} \cdot \mathrm{c}\right)\right)$ и сложного вещества - бензина $\left(\approx 0,05 \kappa \Gamma /\left(\mathrm{M}^{2} \cdot \mathrm{c}\right)\right)[3]$.

Затем, используя формулу (1), рассчитали m' для бензола (получено в результате расчета значение $\mathrm{m}^{\prime}=0,047$ кг/( $\left.\left.\mathrm{M}^{2} \cdot \mathrm{c}\right)\right)$ и для бензина в интервале температур 50-210 ㄷ с учетом изменения плотности в связи с увеличением температуры и выгорания фракций в процессе горения [4-7]. Массовая скорость выгорания бензина в пределах 50-200 ${ }^{\circ} \mathrm{C}$ превысила 0,66 кг/( $\left.\mathrm{M}^{2} \cdot \mathrm{c}\right)$, в пределах $200-210^{\circ} \mathrm{C}$ составила 0,56-0,65 кг/( $\left.\mathrm{M}^{2} \cdot \mathrm{c}\right)$.

Таким образом, можно сделать вывод, что данная формула (1) для расчета m' применима для сложного жидкого топлива с учетом изменения плотности и температуры в процессе горения.

Для упрощения метода определения значения $\mathrm{m}^{\prime}$ для многокомпонентных нефтепродуктов нами разработана номограмма, которая позволяет определить величину m', зная плотность нефтепродукта при нормальных условиях и температуру кипения (значение для фракции в составе нефтепродукта с максимальной температурой кипения, так как в сложном веществе отдельные фракции выкипают при разной температуре). На рисунке 1 приведен пример зависимости величины m' от температуры кипения и плотности для нефти, который применим также для нефтепродуктов с температурой кипения $430-550{ }^{\circ} \mathrm{C}$. 


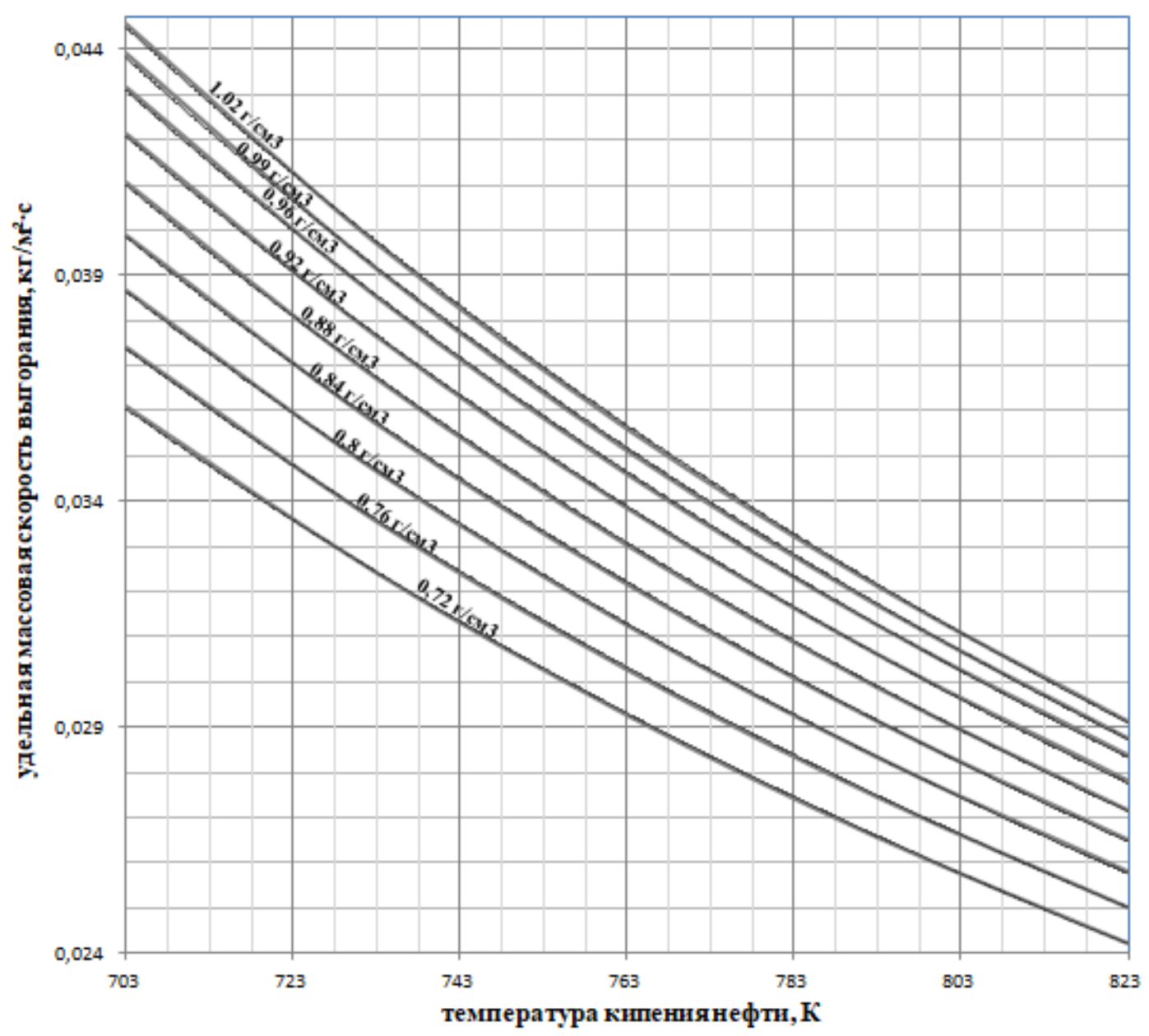

Рисунок 1. График зависимости значения удельной массовой скорости выгорания от плотности и температуры кипения продукта для нефти

Мы уже подтвердили, что формула (1) применима для расчета величины m' сложных нефтепродуктов, однако при этом возникает необходимость расчета величин удельной теплоты сгорания и испарения, удельной теплоемкости при заданном значении температуры, которые можно найти в справочных материалах для ограниченного ряда веществ [4-7]. На основе проведенных нами исследований по определению величины m', а также разработанных нами номограмм мы вывели эмпирическую формулу расчета, позволяющую рассчитать $\mathrm{m}$ ' с использованием минимального числа переменных:

$$
\mathrm{m}^{\prime}=\mathrm{k}_{1} \cdot \ln \left(\rho_{4}^{20}\right)+\mathrm{k}_{2},
$$

где $\mathrm{k}_{1}$ и $\mathrm{k}_{2}$ - коэффициенты, зависящие от разницы между температурой кипения и начальной температурой $\Delta \mathrm{T}$; 
$\rho_{4}^{20}-$ относительная плотность нефтепродукта при нормальных

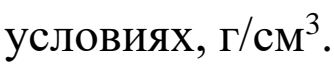

Значения коэффициентов $\mathrm{k}_{1}$ и $\mathrm{k}_{2}$ при $\Delta \mathrm{T}$ в пределах $410-530{ }^{\circ} \mathrm{C}$ определяются по графику, представленному на рисунке 2.

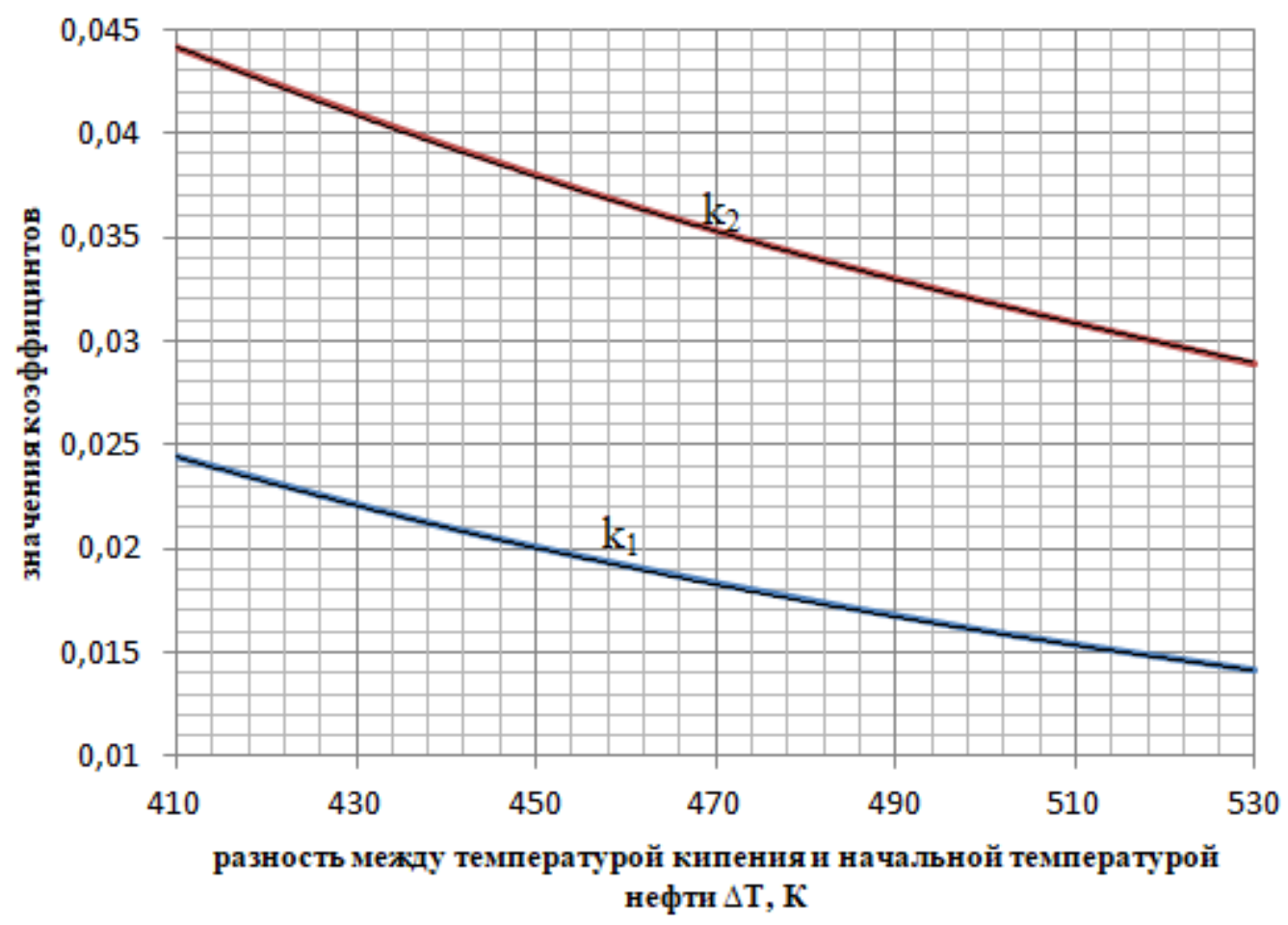

Рисунок 2. График зависимости коэффициентов $\mathrm{k}_{1}$ и $\mathrm{k}_{2}$ от разниц $\Delta \mathrm{T}$ между температурой кипения и начальной температурой

\section{Выводы}

Предложено усовершенствование метода определения удельной массовой скорости выгорания нефтепродуктов, являющихся многокомпонентными, с разработкой номограммы и формулы расчета, которые позволяют определить величину удельной массовой скорости выгорания, зная плотность нефтепродукта при нормальных условиях и его температуру кипения.

Составленная авторами номограмма для определения удельной массовой скорости выгорания нефтепродуктов, а также полученная упрощенная формула расчета величины удельной массовой скорости выгорания для фракций, выкипающих при высоких температурах, 
позволяет упростить метод расчета интенсивности теплового излучения в случае горения топливных смесей и проводить оптимальную оценку пожарных рисков на производственных объектах.

\section{Список используемых источников}

1. Тимофеева С.С., Дроздова Т.И., Плотникова Г.В., Гольчевский В.Ф. Физико-химические основы развития и тушения пожара. Иркутск: ИГТУ, 2013. 174 c.

2. Приказ МЧС РФ от 10.07.2009 № 404 «Об утверждении методики определения расчетных величин пожарного риска на производственных объектах» // Информационно-правовое обеспечение «Гарант». URL: https://base.garant.ru/196118/ (дата обращения: 21.01.2021).

3. Смирнов Н.В. Методика испытаний по определению удельной массовой скорости выгорания твердых веществ и материалов. М.: ВНИИПО, 2014. 17 с.

4. Портола В.А., Луговцова Н.Ю., Торосян Е.С. Расчет процессов горения и взрыва. Томск: Томский политехнический университет, 2012. $108 \mathrm{c}$.

5. Матвеев С.Н. Теория и практика добычи нефти. Сургут: РИИЦ «Нефть Приобья», 2008. 416 с.

6. Хафизов Ф.Ш., Краснов А.В. Давление насыщенных паров для нефтепродуктов // Электронный научный журнал «Нефтегазовое дело». 2012. № 3. C. 406-412. URL: http://ogbus.ru/files/ogbus/authors/KhafizovFSh/ KhafizovFSh_10.pdf (дата обращения: 21.01.2021).

7. Кирсанов Ю.Г. Расчетные и графические методы определения свойств нефти и нефтепродуктов. Екатеринбург: УрФУ, 2014. 136 с. 


\section{References}

1. Timofeeva S.S., Drozdova T.I., Plotnikova G.V., Golchevskii V.F. Fizikokhimicheskie osnovy razvitiya i tusheniya pozhara [Physicochemical Basis for the Development and Extinguishing of a Fire]. Irkutsk, IGTU Publ., 2013. 174 p. [in Russian].

2. Prikaz MChS RF ot 10.07.2009 № 404 «Ob utverzhdenii metodiki opredeleniya raschetnykh velichin pozharnogo riska na proizvodstvennykh $o b^{\prime \prime} e k t a k h$ » [Order of the Ministry of Emergency Situations of the Russian Federation Dated July 10, 2009 No. 404 «On Approval of the Methodology for Determining the Calculated Values of Fire Risk at Production Facilities»]. Informatsionno-pravovoe obespechenie «Garant». Available at: https://base.garant.ru/196118 (accessed 21.01.2021). [in Russian].

3. Smirnov N.V. Metodika ispytanii po opredeleniyu udel'noi massovoi skorosti vygoraniya tverdykh veshchestv $i$ materialov [Test Procedure for Determining the Specific Mass Burnout Rate of Solids and Materials]. Moscow, VNIIPO Publ., 2014. 17 p. [in Russian].

4. Portola V.A., Lugovtsova N.Yu., Torosyan E.S. Raschet protsessov goreniya i vzryva [Calculation of Combustion and Explosion Processes]. Tomsk, Tomskii politekhnicheskii universitet Publ., 2012. 108 p. [in Russian].

5. Matveev S.N. Teoriya i praktika dobychi nefti [Theory and Practice of Oil Production]. Surgut, RIITs «Neft' Priob'ya» Publ., 2008. 416 p. [in Russian].

6. Khafizov F.Sh., Krasnov A.V. Davlenie nasyshchennykh parov dlya nefteproduktov [Pressure of Saturated Steams for Oil Products]. Elektronnyi nauchnyi zhurnal «Neftegazovoe delo» - Electronic Scientific Journal «Oil and Gas Business», 2012, No. 3, pp. 406-412. URL: http://ogbus.ru/ files/ogbus/authors/KhafizovFSh/KhafizovFSh_10.pdf (accessed 21.01.2021). [in Russian].

7. Kirsanov Yu.G. Raschetnye i graficheskie metody opredeleniya svoistv nefti $i$ nefteproduktov [Calculation and Graphical Methods for Determining the Properties of Oil and Oil Products]. Yekaterinburg, UrFU Publ., 2014. 136 p. [in Russian]. 


\section{Сведения об авторах}

\section{About the authors}

Хуснутдинова Сумбуль Муталовна, аспирант кафедры «Пожарная и промышленная безопасность», УГНТУ, г. Уфа, Российская Федерация

Sumbul M. Khusnutdinova, Post-graduate Student of Fire and Industrial Safety Department, USPTU, Ufa, Russian Federation

e-mail: sumbulryamova993@gmail.com

Хафизов Фаниль Шамильевич, д-р техн. наук, профессор, заведующий кафедрой «Пожарная и промышленная безопасность», УГНТУ, г. Уфа, Российская Федерация

Fanil Sh. Khafizov, Doctor of Engineering Sciences, Professor, Head of Fire and Industrial Safety Department, USPTU, Ufa, Russian Federation

e-mail:pkpb@mail.ru

Хафизов Ильдар Фанилевич, д-р техн. наук, профессор кафедры «Пожарная и промышленная безопасность», УГНТУ, г. Уфа, Российская Федерация

Ildar F. Khafizov, Doctor of Engineering Sciences, Professor of Fire and Industrial Safety Department, USPTU, Ufa, Russian Federation

e-mail:pkpb@mail.ru

Мингазетдинов Расим Фавасимович, ассистент кафедры «Пожарная и промышленная безопасность», УГНТУ, г. Уфа, Российская Федерация

Rasim F. Mingazetdinov, Assistant of Fire and Industrial Safety Department, USPTU, Ufa, Russian Federation

e-mail:pkpb@mail.ru 